\title{
Body Surface Area Formula
}

National Cancer Institute

\section{Source}

National Cancer Institute. Body Surface Area Formula. NCI Thesaurus. Code C68645.

A mathematical formula for calculating the body surface area for an organism. 